\title{
Staying Connected: Online Education Engagement and Retention using Educational Technology Tools
}

\author{
JOSE SALAZAR
}

\begin{abstract}
The objective of this article is to inform educators about the use of currently available educational technology tools to promote student retention, engagement and interaction in online courses. Educational technology tools include content management systems, podcasts, video lecture capture technology and electronic discussion boards. Successful use of educational technology tools requires planning, organization and use of effective learning strategies.
\end{abstract}

KEYWORDS: online education; educational technology; engagement; retention

\section{LEARNING OBJECTIVES}

1. Define educational technology.

2. List 4 educational technology tools used to enhance the delivery of interactive online education.

3. Discuss the overall impact of educational technology tools on online education.

4. Describe 2 major causes for high attrition in online education.

5. Identify and describe 2 interactive methods that result in increased engagement and retention of online students.

Clin Lab Sci 2010;23(3)Suppl;3-53

Jose Salazar, MS, MLS(ASCP) $)^{C M}$, Department of Clinical Laboratory Sciences, University of Texas Medical Branch, Galveston, Texas 77555

Address for Correspondence: Jose Salazar, MS, MLS(ASCP $)^{C M}$, Clinical Assistant Professor, Department of Clinical Laboratory Sciences, University of Texas Medical Branch, 301 University Boulevard, Galveston, Texas 77555, 409-772-3044, jhsalaza@utmb.edu

\section{INTRODUCTION}

The rapid evolution of computer technology has promoted the expansion of educational borders, both physical and mental, by allowing today's students to virtually join the classroom via online education. More recently, online education has increasingly been delivered in electronic forms, such as web-conferencing, course management systems and wireless mobile devices. ${ }^{1}$ The internet has spawned a new generation of users who depend on computers for daily tasks ranging from paying bills to keeping up with friends via social networks. As students become more accustomed to the internet and the interaction it has brought to their online experience, they expect their online education to use similar applications for their learning experiences. There are major differences in an online teaching environment when compared to a face-to-face class. ${ }^{2}$ It is important to differentiate between the competency of web surfing to that of completing actual coursework online. The additional options of the internet can enhance the learning experience and be used to teach to a variety of learning styles, but it also requires faculty to rethink how they teach and how they engage online students.

The use of educational technology, combined with a pedagogically sound curriculum, can be a powerful combination to engage and successfully graduate online students. Educational technology is defined as addressing educational needs using networked computers and mobile devices. ${ }^{3}$ Online learning outcomes and retention rates at least equal or exceed traditional classroom learning environments when instructors use a systematic design process to develop online courses. Dziuban et al. compared success and withdraw rates using an instructional design model and found that environments that support faculty development, promote organizational skills, and provide course 


\section{FOCUS: EDUCATIONAL TECHNOLOGY}

development assistance have a direct positive impact on student learning. ${ }^{3}$

Additionally, identifying the needs and expectations of the students in an online class plays an important role in creating a working relationship between the instructor and the students and results in increased student engagement and the establishment of an online virtual community. According to Ezarik, the majority of distance learners are older than 27, first-generation college students and enrolled part-time. They spend more time working and caring for dependents than oncampus students. Students who have the ability to be consistent, structured, and organized are more successful in an online course. By understanding the dynamics of online students an instructor can create a learning environment that allows the students to learn effectively, while interacting at their own pace and time.

\section{Implementing Educational Technology}

Educational technology has revolutionized the way education can be delivered and how it can be customized for maximal impact in an online environment. The measurable impact on students' learning depends on the way educational technology is used and the conditions under which it is implemented. ${ }^{4}$ The implementation of online educational technology requires administration support, technical staff guidance and ample course development time. Educational technology does not replace effective learning strategies, but requires that the strategies be implemented in a manner that makes the best use of the technology. For example, discussions that take place in face to face classrooms can be mimicked to provide a similar learning experience by using discussion boards or chat rooms. Using this technology, the learning experience is enhanced because discussions are captured and can be reviewed later by students and instructors.

\section{Student Engagement and Retention}

Online education works best when it is not treated as a self-serve package. Creating meaningful interactions is of paramount importance to engage an online student. The following steps outline a series of recommendations that an online instructor should follow to successfully deliver an online course.

3-54 VOL 23, NO 3 SUMMER 2010 SUPPLEMENT CLINICAL LABORATORY SCIENCE
1. Distribute information on how to access the course online in an efficient and timely manner. For example, the instructor can host an orientation session so that online students will know where general course information is located and whom to contact if they have course content issues or technical problems with technology. To prevent procrastination, instructors should mandate orientation within the first week of class.

2. The online instructor must develop the course with a structured online platform. All course content should be well thought-out so that it is intuitive for the student to locate basic information such as the course syllabus, schedule, learning objectives, content, and assignments. The majority of universities are now adopting course management systems (CMS) such as Moodle ${ }^{\circledR}, \mathrm{Sakai}^{\circledR}$, Blackboard $^{\circledR}$, Angel $^{\circledR}$ or WebCT ${ }^{\circledR}$. These systems allow instructors to distribute and manage course materials in a password-secured central location.

3. Instructors should introduce themselves early in the course to establish an online presence. For example, instructors can create a self-introduction video clip or an interactive bio. Online students perform well when they experience a sense of community between their instructor and fellow peers. ${ }^{5,6}$ Groups function well through online interactions between instructor-student and student-student that create an environment similar to a classroom. Educational tools such as podcasts, chat or discussion boards can be used to initiate contact.

4. Get the students involved early in the course. Ask students to utilize the educational tools to introduce themselves. Discussion forums, internal student web pages, and student groups are applications that allow both instructors and students to share information quickly and to specific groups. For example, at the beginning of the course, ask students to post a short biography with a picture. A more interactive approach involves students posting a short video clip showcasing themselves as they share parameters indicated by the course instructor.

5. Provide timely feedback. Maintain consistent contact with students regarding progress, graded assessments and student ideas. According to Hannum, students in 


\section{FOCUS: EDUCATIONAL TECHNOLOGY}

successful programs were well-supported by strong orientation sessions, a single point of contact for students, and frequent instructor feedback. ${ }^{7}$

The same study found the most common reasons for attrition were students realization that the medium did not fit their learning style, minimal instructor interaction and lack of course information. ${ }^{7}$ Reducing attrition rates among online education programs is a major concern. Online courses require just as much planning, organization and use of effective learning strategies as traditional face to face courses. For instance, virtual simulations and web chats mimic elements of traditional classroom experience. ${ }^{1}$ Instructors can design their courses to include group activities and assessments that support writing, viewing, listening, comprehension, and synthesis. These activities pull in the student in a collaborative effort thus promoting student-student learning interactions and address the wide variety of learning styles. Further, if online courses are designed to incorporate educational technology in a student/instructor friendly manner, and if students are oriented to the tools, there is an increased possibility that reflective learning can be achieved and that the learning is adaptive, communicative, productive, narrative, and interactive. ${ }^{8}$ By using educational technology to its full potential, student learning can be improved and factors that contribute to online student attrition are minimized.

A number of educational technology tools that enhance online course learning have been introduced in the past decade. Podcasts, wikis, course management systems, and videoconferencing via internet protocol (IP) are just a few of the tools now available. These educational technology tools can be used to increase the amount of interactivity in an online course, thus resulting in a higher degree of student engagement and retention.

\section{Educational Technology Tools}

Synchronous audio and video delivery can be delivered live. One method available to accomplish synchronous video and audio delivery is called web-conferencing or Webinars. Several web-conferencing services and software downloads are available at no cost along with media license packages that education institutions may purchase and maintain. Web-conferencing allows synchronous connections among multiple locations. High-speed broad-band internet connections are required. The hardware requirements include a computer, web camera and microphone. Web conferencing allows for the creation of a sense of community and serves as an ice breaker between the instructor and the enrolled students.

Asynchronous online course interaction can be achieved by recording the session using the same technology as is used in web conferencing. Instead of delivering the content live, it is stored on a server with video streaming capabilities. Students are then able to stream or download the recorded content at a time that aligns with their schedule. Video lecture capture technology (VLCT) is very similar to web-conferencing except that it is set up for continuous video capture of classroom lectures. VLCT supports student retention by engaging students, increasing student satisfaction, and promoting student achievement. ${ }^{9}$ Every class is captured in a combination of both audio and video format using computers and the internet for capture, processing and delivery. There is no need to process tapes or hire a film crew. The VLCT is distributed to students through an online course management system. Students are then able to review the captured materials anytime, anywhere. VLCT provides instructors with a teaching strategy that resonates with students accustomed to multimedia. Instructors initiate recording software before beginning their class lecture. The software records the lecture and provides video feeds of the instructor and the presentation (PowerPoint, for example). The captured content is uploaded to a server that makes the content available to students within an hour. Students who have logins are able to view the lectures from any computer device connected to the internet. Further, students may also download the audio/video content as podcasts and vodcasts to off-line computers and mobile devices thus allowing them to access the content without an internet connection. VLCT is also used to engage students in the class environment, particularly if they are joining asynchronously. A student can record content that is to be shared with classmates. For example as an interactive case study assignment, students can use the VLCT to record a case study at home, upload the presentation 


\section{FOCUS: EDUCATIONAL TECHNOLOGY}

and easily distribute it to fellow classmates and instructors for peer review or grading.

Course management systems (CMS) are web-based platforms that allow instructors and students to securely access course materials, multi-media files, assessment tools, email, chats and discussions from a central site. ${ }^{9}$ Students utilize the CMS as the hub for their course interactions. CMS provides a rich environment an instructor can use to engage students by way of synchronous and asynchronous communication in an organized structure. Course information and content are organized and accessible. Good CMS programs are designed to be intuitive and consistent. A benefit of using CMS is its flexibility. CMS are easily customizable to provide a canvas for instructors to deliver a course. Some CMS structures are too flexible, providing more than one way to organize materials. This can be confusing.

An organizational plan must be developed before course materials are added to the CMS. When a user enters the course, a concise menu should appear. Too many menu choices will confuse and distract the user. Design the CMS so that the most basic and important pieces of information make up the course appear first. Menu items such as Announcements, Course Syllabus, Course Materials, Assignments, and Resources are deemed concise and appropriate for a course welcome page. Announcements should contain time-dependent information. Content changes, schedule updates, deadlines, and other timely information are appropriate under the announcement menu item.

Under the Course Syllabus heading, general course policies and the course schedule should be housed. Course Materials can be used to organize the course content, consisting of outlines, learning modules, slide shows and PowerPoint lectures notes. The Assignments area can include quizzes, exams, and individual assignment units. Under Resources, post internal and external links. Other menu items may be added as necessary.

Another area which is useful in CMS is the submission of assignments. Not only can the assignments be made available, but students can also submit them via assignment boxes that deliver files directly into the CMS instead of the instructor's email. The process is a well-orchestrated exchange between instructor and student. To implement online submissions the instructor creates an assignment module within the CMS. Pedagogically-based models of online modules in the CMS involve the use of assignment learning objectives, grading criteria, and instructions for successful completion within the module. During this process the CMS automatically creates a "digital drop box" area for the student to electronically submit their completed assignment. The CMS grade center automatically creates a column in the grade center (grade book) that is accessible only to the instructor. The instructor then has the option of sending an announcement to students via the CMS email system indicating that an assignment has been posted and is ready for the student to download. The student retrieves the assignment via download from the CMS. The assignment is completed and uploaded to the respective "digital drop box" and is stored in the grade center ready to be reviewed by the instructor. The instructor now has the opportunity to download all submitted assignments from one location. A tremendous benefit is the ability to provide immediate feedback to graded work in the form of written comments along with the earned grade. The student can track and review submissions, instructor comments, and earned grades as the course progresses. This mechanism facilitates the interaction between the instructor and student regarding the exchange of work that is assigned and submitted for assessment. Further, the feedback opportunity aligns with the goal of consistent and frequent communication with students.

Through CMS tracking mechanisms an instructor can identify and reach students who are at risk for attrition or failure. By recording and storing grades in a CMS, the tracking feature allows the instructor to nonintrusively mine and analyze student data. ${ }^{9}$ Once high risk students are identified, the instructor can contact the student to initiate remediation that increases retention and successful completion of the course.

Communication tools found in CMS, such as discussion forums, blogs, and chat rooms, play an important role in enhancing the interactivity between instructor and 


\section{FOCUS: EDUCATIONAL TECHNOLOGY}

students as well as student to student communications. An interactive discussion board can include consistent and meaningful posts from both the instructor and student. In some instances, it is appropriate for the instructor to begin a thread and only moderate the discussion as needed. Blogs (web logs) are online diaries that can be hosted securely. Blogs can be used by students to express their opinions on issues related to the course of study. Peers have access to each other's blogs and are able to review other classmates' perception of the material. Only the owner of the blog can contribute commentaries, images or videos to the blog.

A wiki, also known as collaborative software, is a great tool to stimulate group work. Wikis allow a group of students to post documents within the CMS and render it available to any member for updates and editing. The wiki monitors and organizes the activity.

Podcasting is an audio/video medium (video is also known as vodcast) in which information is delivered via real simple syndication (RSS) feeds. ${ }^{11}$ The producer needs a computer, microphone and webcam if video is to be recorded. The author records content with a sound capture program that uploads the audio files to a server that hosts RSS feeds. Users can then program their MP3 player client to download RSS feeds. Educators can reach online students by creating podcasts that are informative and related to course progress. Supplemental podcasts are a very popular source of quick up-to-date information that can engage students as they progress through their course work.

Learning objects (LOs) are tools that captivate the attention of learners of all learning styles. LOs are instructional material broken down into pieces that can be used independently or in conjunction with other materials. ${ }^{13}$ Concepts that are difficult to teach are prime candidates for creation of LOs. LOs allow the instructor to spread abstract topics into elementary teaching pieces using technology that incorporates visual and audio cues. LOs can be images, animations, or text modules that are transportable and reusable. The creation of LOs begins with the idea of identifying specific topics students have difficulty understanding. Once an area is identified, work begins with a computer programmer or multi-media specialists along with the instructor as the subject matter expert. LOs can be disseminated online via a CMS or an LO repository such as http://webcls.utmb.edu/lo. Students are able to download LOs and use them to enhance their learning experience.

\section{CONCLUSION}

Students now expect to use technology in all aspects of their lives, including education. Why not engage them by providing an interactive learning environment that will enhance their skills? Educational technology tools convert the online learning environment into a canvas ideal for interaction. Taking the classroom to the virtual world is the wave of the future. Let us embrace technology and harness its power to engage and stimulate students of today and the future.

\section{REFERENCES}

1. Ashby, C. Distance Education, Growth in Distance Education Programs and Implications for Federal Education Policy. 2002, Report No. GAO-02-1125T). United States General Accounting Office. Retrieved March 5, 2010 from http://www.gao.gov/new.items/d021125t.pdf

2. Price L, Richardson J, Jelfs A. Face-to-face versus online tutoring support in distance education. Studies in Higher Education 2007;32: 1-20. Retrieved March 1, 2010 from Academic Search Complete database

3. Dziuban C, Hartman J, Moska, P. Blended Learning. Educause Research Bulletin, 2004; 1-4. Retrieved March 18, 2010. from http://net.educause.edu/ir/library/pdf/ERB0407.pdf

4. Roblyer M. Integrating Educational Technology into Teaching (4th edition). Upper Saddle River, NJ: Pearson Prentice Hall 2006

5. Ezarik M. Going the distance on engagement. University Business (2006); 9: 17. Retrieved March 5, 2010 from Academic Search Complete database.

6. Drouin M. The relationship between students' perceived sense of community and satisfaction, achievement, and retention in an online course. Quarterly Review of Distance Education 2008; 9: 267-84. Retrieved March 1, 2010 from Academic Search Complete database.

7. Hannum W, Irvin M, Lei P, Farmer T. Effectiveness of using learner-centered principles on student retention in distance education courses in rural schools. Distance Education 2008; 29: 211-29. doi:10.1080/01587910802395763 March 1, 2010.

8. Stover C. Measuring—and understanding—student retention. Distance Education Report 2005:9:1-7. Retrieved March 1, 2010 from Academic Search Complete database.

9. Gillies D. Student perspectives on videoconferencing in teacher education at a distance. Distance Education, 2008;29:107-18. doi:10.1080/01587910802004878 March 1, 2010. 
10. Morgan J, Rawlinson M, Weaver M. Facilitating online reflective learning for health and social care professionals. Open Learning 2006;21:167-76. doi:10.1080/02680510600715594 March 1, 2010.

11. Macfadyen L, Dawson S. Mining LMS data to develop an "early warning system" for educators: A proof of concept.
Computers \& Education 2010, 54:588-99. doi:10.1016/j.comp edu.2009.09.008 March 1, 2010.

12. Garrett N. New technologies help build learning communities. Distance Education Report 2006; 10:1-6. Retrieved March 5, 2010 from Academic Search Complete database.

13. Brickell J, Kanuth M, Freeman VS. Learning objects: resource for instruction. Clin Lab Sci 2006; 19:184-7.

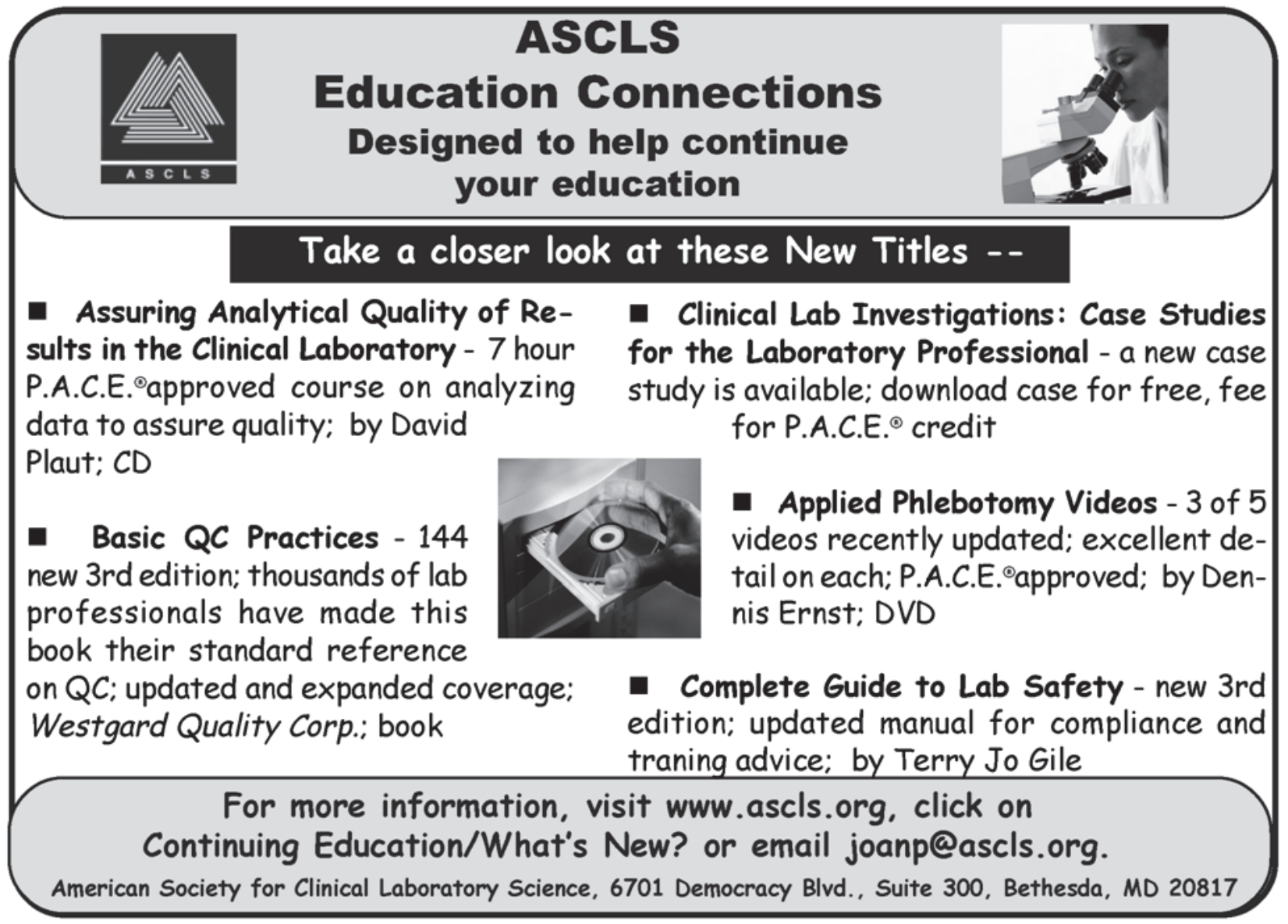

